\title{
Management of Overt Hepatic Encephalopathy
}

\author{
Praveen Sharma*, Barjesh C. Sharma \\ *Department of Gastroenterology, Sir Ganga Ram Hospital and'Department of Gastroenterology, G. B. Pant Hospital, New Delhi, India
}

\begin{abstract}
Hepatic encephalopathy (HE) is an important complication of cirrhosis with significant morbidity and mortality. Management of HE primarily involves avoidance of precipitating factors and administration of various ammonia-lowering therapies such as non-absorbable disaccharides, antimicrobial agents like rifaximin and L-ornithine L-aspartate. The non-absorbable disaccharides which include lactulose and lactitol are considered the first-line therapy for the treatment of $\mathrm{HE}$ and in primary and secondary prophylaxis of HE. Lactitol is comparable to lactulose in the treatment of $\mathrm{HE}$ with fewer side effects. Rifaximin is effective in treatment of $\mathrm{HE}$ and recent systemic reviews found it comparable to disaccharides and is effective in secondary prophylaxis of HE. Many agents like L-ornithine L-aspartate, probiotics, zinc, sodium benzoate have been tried either alone or in combination with lactulose for the treatment of HE. Combination therapy of disaccharides either with rifaximin, L-ornithine L-aspartate, probiotics for the treatment of $\mathrm{HE}$ needs further validation in large studies. (J CLIN EXP HePATOL 2015;5:S82-S87)
\end{abstract}

$\mathrm{H}$ epatic encephalopathy (HE) is a complex neuropsychiatric syndrome, which may complicate acute, chronic liver failure or patients with portal-systemic shunting. It is characterized by changes in mental state including a wide range of neuropsychiatric symptoms ranging from minor signs of altered brain function to deep coma. ${ }^{1,2}$ It is one of the commonest indications for admission in intensive care unit in patients with advanced cirrhosis. There were over 40000 patients hospitalized in the United States alone for a primary diagnosis of $\mathrm{HE}$, resulting in total charges of approximately $\$ 932$ million. Data in other countries are lacking, hence it causes a huge burden financially to the patient and society. ${ }^{3}$

The West Haven Criteria are most often used to grade $\mathrm{HE}$, with scores ranging from I-IV (IV being coma). However, it is a challenge to diagnose patients with minimal hepatic encephalopathy (MHE) or grade $1 \mathrm{HE}$; so it might be practical to combine these entities and name them covert HE for clinical use and overt HE to patients with grade II to IV. ${ }^{1,4,5}$ One of the major tenets of the pathophysiology of HE is hyperammonemia that results from an increased nitrogenous load from the gastrointestinal tract and reduced urea synthesis both due to portal-systemic shunting and decreased urea hepatic synthesis. Brain and skel-

Keywords: hepatic encephalopathy, disaccharides, lactulose

Received: 23.1.2014; Accepted: 16.4.2014; Available online: 10.5.2014

Address for correspondence: Barjesh C. Sharma, Department of Gastroenterology, G.B. Pant Hospital, New Delhi, India.

E-mails: drbcsharma@hotmail.com; drpraveen_sharma@yahoo.com Abbreviations: HE: hepatic encephalopathy; MHE: minimal hepatic encephalopathy; TIPS: transjugular intrahepatic portosystemic shunt; HR: hazard ratio

http://dx.doi.org/10.1016/j.jceh.2014.04.004 etal muscle neither remove nor produce ammonium in normal conditions, but they are able to seize ammonium during hyperammonemia, releasing glutamine. Ammonia is produced both by bacterial degradation of amines, aminoacids, purines, and urea as well as enterocytic glutaminase activity that converts glutamine to glutamate and ammonia. ${ }^{6,7}$ Astrocytes play an important role in the pathogenesis of HE with consequences for neuronal function. Astrocytes have the ability to eliminate ammonia by the synthesis of glutamine through amidation of glutamate by the enzyme glutamine synthetase Hyperammonemia leads to the accumulation of glutamine within astrocytes, which exerts an osmotic stress that causes astrocytes to take in water and swell. ${ }^{8,9}$

This article reviewed the clinical impact, pathogenesis, and management of overt HE in patients with cirrhosis. Articles published between January 1960 and November 2013 were acquired through a MEDLINE search of different combinations of the terms hepatic encephalopathy, pathophysiology, treatment, prophylaxis, prognosis, and recurrence. Randomized trials, open-labeled trials and meta-analysis on HE which were published in English literature were included for this review.

\section{THERAPY FOR HEPATIC ENCEPHALOPATHY AND ROLE OF NON-ABSORBABLE DISACCHARIDES}

The first step in treatment of HE is identifying and treating precipitating causes which includes management of hypovolemia, gastrointestinal bleeding, infection, excessive diuretic use, diarrhea, vomiting, hyponatremia, hypokalemia or hyperkalemia, constipation, 
benzodiazepine use and noncompliance with lactulose or rifaximin therapy. ${ }^{2}$

\section{Non-absorbable Disaccharides and Mechanism of Action}

Current therapies for HE are based on ammonia-lowering with the hypothesis that the colon is the primary organ that generates ammonia. Non-absorbable disaccharides have been the first-line drug treatment for lowering the production and absorption of ammonia., ${ }^{2,10}$ Disaccharides (lactulose and lactitol) get metabolized by the bacteria in the colon to acetic and lactic acid. This acidification of the colon not only creates a hostile environment for the survival of intestinal bacteria with urease activity involved in the production of ammonia in the gut, but also facilitates the conversion of $\mathrm{NH} 3$ to non-absorbable NH4+. Both effects result in reduced levels of ammonia in the colon and portal blood. Nonabsorbable disaccharides also cause a 4-fold increase in faecal nitrogen excretion due to their cathartic effect. ${ }^{11,12}$

Lactulose is the most commonly utilized nonabsorbable disaccharide for HE. Lactulose, a synthetic disaccharide, is comprised of the monosaccharides lactose and galactose, and is available as syrup and powder. Similarly lactitol (p-galactosido-sorbitol) is a disaccharide analog of lactulose which is neither absorbed nor broken down in the small intestine. Doses are generally titrated to achieve two to four semi-soft stools daily.

\section{Clinical Efficacy of Non-absorbable Disaccharides}

The non-absorbable disaccharides have been a mainstay of therapy for HE for decades, and have been extensively studied in several small clinical trials. Oral lactulose was used in majority of these studies though some had used lactitol and lactulose enemas also. ${ }^{13,14}$ In most of the studies the daily mean doses of lactulose ranged from $30 \mathrm{~g}$ to $80 \mathrm{~g}$ (median $50 \mathrm{~g}$ ) to obtain two to three semi-soft stools per day. The median duration of treatment was 15 days (range 5-360 days). Lactitol has also been used in treatment of HE and meta-analysis showed no statistical differences in percentage of improved patients after lactitol or lactulose while slightly higher frequency of flatulence in patients treated with lactulose compared with lactitol ${ }^{15-19}$ (Table 1).

A recent meta-analysis evaluated 22 clinical trials in order to better assess the utilization of non-absorbable disaccharides in the management of HE when compared with placebo, no intervention or antimicrobials. Compared with placebo or no intervention, lactulose and lactitol seemed to reduce the risk of no improvement of hepatic encephalopathy (relative risk $0.62,95 \%$ confidence interval $0.46-0.84)$. However high quality trials found no significant effect of lactulose or lactitol on the risk of no improvement (0.92, 0.42-2.04), whereas low quality trials found a significant beneficial effect of lactulose or lactitol $(0.57$, $0.40-0.83) .{ }^{20}$ Most of the studies were carried out in adults however lactulose has shown to be effective in the treatment of HE in children also. ${ }^{21}$ At present time, however, there is a lack of sufficient evidence to thoroughly refute the use of non-absorbable disaccharides for the treatment of HE. We analyzed the factors associated with nonresponse to lactulose therapy and found that high baseline MELD, high total leukocyte count, low serum sodium, low MAP, and presence of hepatocellular carcinoma were predictors of nonresponse to lactulose. ${ }^{22}$

\section{ANTIMICROBIAL AGENTS FOR HEPATIC ENCEPHALOPATHY}

Antimicrobial agents have long been utilized for the treatment of patients with overt HE. Neomycin and other antimicrobials are utilized as a treatment modality in HE due to their ability to inhibit ammonia production by intestinal bacteria. ${ }^{23}$ Other antimicrobials, including metronidazole and vancomycin, have been studied to a more limited extent than neomycin. ${ }^{24,25}$

\section{Rifaximin for Hepatic Encephalopathy}

Rifaximin is a poorly absorbed synthetic antimicrobial with a broad spectrum of antibacterial activity. Both

Table 1 Comparison of Non-absorbable Disaccharides and Placebo or No Treatment for Hepatic Encephalopathy.

\begin{tabular}{|c|c|c|c|c|c|c|}
\hline Trial & Study design & Patients & No & Treatment & Assessment & Efficacy \\
\hline Simmons et al ${ }^{13}$ & Parallel & $\mathrm{AHE}+\mathrm{CHE}$ & 26 & Lactulose/glucose & Clinical grading, ammonia, stool production & Lactulose $=$ glucose \\
\hline Uribe et $\mathrm{al}^{14}$ & Parallel & AHE & 15 & $\begin{array}{l}\text { Lactulose } \\
\text { enema }\end{array}$ & Mortality, clinical grading & Lactulose $>$ placebo \\
\hline Lanthier et $\mathrm{al}^{15}$ & Crossover & $\mathrm{CHE}$ & 5 & 6 months & $\begin{array}{l}\text { Clinical examination, psychometric tests, } \\
\text { ammonia levels, EEG, cerebral blood flow }\end{array}$ & Lactulose $=$ lactitol \\
\hline Heredia et $\mathrm{al}^{16}$ & Parallel & AHE & 40 & 5 days & $\begin{array}{l}\text { Mortality, clinical grading, PSE grade, } \\
\text { adverse events }\end{array}$ & Lactulose $=$ lactitol \\
\hline Riggio et $\mathrm{al}^{17}$ & Parallel & $\mathrm{CHE}+\mathrm{MHE}$ & 31 & 6 months & $\begin{array}{l}\text { PSE index, new episodes of HE, adverse } \\
\text { events }\end{array}$ & Lactulose $=$ lactitol \\
\hline
\end{tabular}

AHE: acute hepatic encephalopathy; CHE: Chronic hepatic encephalopathy; MHE: Minimal hepatic encephalopathy; EEG: Electroencephalography. 
experimental and clinical pharmacology clearly show that this compound is a non-systemic antibiotic with a broad spectrum of antibacterial action covering Gram-positive and Gram-negative organisms, both aerobes and anaerobes. Being virtually non-absorbed, its bioavailability within the GI tract is rather high with intraluminal and fecal drug concentrations that largely exceed the minimal inhibitory concentration values observed in vitro against a wide range of pathogenic organisms. Due to its low rate of systemic absorption, rifaximin appears to be relatively safe. ${ }^{26}$ Many studies have demonstrated the efficacy of rifaximin in the treatment of overt HE (grade $\geq 1)^{27-32}$ (Table 2). In a meta-analysis by Nielsen et $\mathrm{al}^{20}$ compared with antibiotics, patients taking rifaximin had a significant lower risk of no improvement of HE than those taking lactulose or lactitol alone.

However in another two recent meta-analysis including more trials and higher number of patients rifaximin is not superior to non-absorbable disaccharides for acute or chronic hepatic encephalopathy in the long-term or short-term treatment except that it may be better tolerated. ${ }^{31,32}$ However it must be kept in mind that some of the studies enrolled in these metaanalysis are poor quality studies and hence may affect the conclusion of these metaanalysis. Hence we conclude that rifaximin is equally effective in the management of overt $\mathrm{HE}$ as disaccharides.

\section{Comparison of Rifaximin with Other Antibiotics}

Rifaximin has been compared with other antibiotics (e.g. neomycin, paromomycin) in the treatment of HE. ${ }^{27,33-35}$ In a randomized, double-blind study, rifaximin $1200 \mathrm{mg} /$ day $(n=15)$ was compared with neomycin $3 \mathrm{~g} /$ day $(n=15)$ in 30 patients with cirrhosis and stage $1-3$ HE. $^{33}$ After 21 days of treatment, neuropsychiatric symptoms and blood ammonia concentrations were significantly reduced vs. baseline in both groups; however, reduction in blood ammonia concentrations was significantly greater with rifaximin treatment vs. neomycin. Although no patient administered rifaximin experienced adverse events, $26 \%$ of patients administered neomycin showed increases in blood urea nitrogen and plasma creatinine levels, and $33 \%$ reported nausea, abdominal pain and vomiting.

\section{OTHER THERAPY FOR HEPATIC ENCEPHALOPATHY}

\section{Probiotics}

Probiotics have shown to be effective in the treatment of HE. Loguercio et $\mathrm{al}^{36,37}$ showed that long-term administration of Enterococcus faecium (SF68) is at least as useful as lactulose for the chronic treatment of chronic HE. In a meta-analysis by McGee et $\mathrm{al}^{38}$ probiotics were compared with lactulose, there were no significant differences in lack of recovery (3 trials, 173 participants; 47/87 (54\%) versus $44 / 86$ (51\%): RR 1.05 ; 95\% CI 0.75-1.47) and adverse events ( 2 trials, 111 participants; $3 / 56(5 \%)$ versus $6 / 55$ (11\%): RR 0.57; 95\% CI 0.06-5.74). However regular use of probiotics in the management of HE still need more data, its use in management of high grade HE is lacking and different strains may have different effects on HE should be kept in mind.

\section{Sodium Benzoate}

Sodium benzoate reduces serum ammonia levels by increasing ammonia excretion in urine; however, limited data support the benefits of sodium benzoate therapy for HE. One prospective study compared the efficacy of sodium benzoate ( $5 \mathrm{~g}$ twice a day, $n=38$ ) with lactulose $(n=36)$ in patients with cirrhosis or surgical portosystemic anastomosis who presented with an HE exacerbation. Sodium benzoate was found to be comparable to lactulose $(80 \%$ vs $81 \%)$ with similar adverse effect profile. ${ }^{39}$

\section{BRANCHED CHAIN AMINO ACID}

Branched chain amino acid has shown some promising results however meta-analysis of eleven randomized trials

Table 2 Rifaximin for Hepatic Encephalopathy.

\begin{tabular}{|c|c|c|c|c|c|}
\hline Trial & Study design & $\begin{array}{c}\text { No of } \\
\text { patients }\end{array}$ & $\begin{array}{l}\text { Duration of } \\
\text { treatment }\end{array}$ & Assessment & Efficacy \\
\hline Festi et $\mathrm{al}^{27}$ & Lactulose (open-label) & 21 & 21 & $\begin{array}{l}\text { Neurological signs of HE, asterixis score, } \\
\text { HRNB, EEG, ammonia levels }\end{array}$ & Rifaximin = lactulose \\
\hline Massa et $\mathrm{al}^{28}$ & Lactulose (double-blind) & 40 & 15 & $\begin{array}{l}\text { HE index severity, mental status, cancellation } \\
\text { tasks, HRNB, EEG }\end{array}$ & Rifaximin > lactulose \\
\hline Mas et $\mathrm{al}^{29}$ & Lactitol (double-blind) & 103 & 5-10 days & $\begin{array}{l}\text { Mental status, asterixis score, EEG, ammonia } \\
\text { levels, PSE index, psychometric tests }\end{array}$ & Rifaximin = lactitol \\
\hline Paik et $\mathrm{al}^{30}$ & Lactulose (open-label) & 54 & 7 days & $\begin{array}{l}\text { Ammonia levels, flapping tremor, } \\
\text { mental status, HE index, psychometric tests }\end{array}$ & Rifaximin = lactitol \\
\hline Jiang et $\mathrm{al}^{31}$ & Meta-analysis & 264 & - & - & Rifaximin = disaccharides \\
\hline Eltawil et $\mathrm{al}^{32}$ & Meta-analysis & 565 & - & - & Rifaximin $=$ disaccharides \\
\hline
\end{tabular}


(556 patients) assessing BCAA versus carbohydrates, neomycin/lactulose, or isonitrogenous control were included and found no evidence of an effect of BCAA on improvement of HE in trials with adequate generation of the allocation sequence (RR 1.01, 95\% CI 0.84-1.23), three trials. $^{40}$

However in a recent meta-analysis the quantitative analyses included data from 8 trials $(n=382$ patients). Individual patient data were retrieved from 4 trials to recalculate outcomes ( $n=255$ patients). The mean dose of the oral BCAA supplements was $0.25 \mathrm{~g} /(\mathrm{kg}$ body weight $/ \mathrm{d})$. Random effects meta-analysis showed that improvements in HE manifestations were registered for 87 of 172 patients in the BCAA group compared with 56 of 210 controls [risk ratio $=1.71(95 \%$ CI: $1.17,2.51)]$ BCAA supplements had no effect on mortality or markers of nutritional status and did not induce adverse events. It concluded that, oral BCAA supplements improve manifestations of HE but have no effect on survival. ${ }^{41}$ However its role in management of HE still needs more data to use in higher grade of HE.

\section{L-Ornithine-L-Aspartate}

L-ornithine-L-aspartate lowers serum ammonia levels by providing substrates for the intracellular metabolic conversion of ammonia to urea and glutamine.

Results from controlled trials suggest that ornithineaspartate reduces ammonia levels and provides therapeutic benefits in patients with chronic mild to moderate HE. One study using intravenous ornithine-aspartate $20 \mathrm{~g} /$ day for 7 days with placebo in 126 patients with cirrhosis, hyperammonaemia (>50 lmol/L) and chronic HE. Ornithine-aspartate significantly improved venous ammonia concentration $(P<0.01)$, mental status $(P<0.001)$ and PSE index $(P<0.01) .{ }^{39}$ These findings point to L-ornithine-L-aspartate (LOLA) as a promising HE treatment that deserves further evaluation. ${ }^{42}$ Metaanalysis of eight randomized controlled trials with 646 patients comparing placebo/no-intervention control, LOLA was significantly more effective in the improvement of $\mathrm{HE}$ in the total (RR: 1.49, 95\% confidence interval [CI]: 1.10 2.01), overt HE (RR: 1.33, 95\% CI: 1.04-1.69). The tolerance ratio, incidence of adverse events, and mortality were not significantly different between LOLA and the placebo/nointervention control. ${ }^{43}$ However in most of the studies low grade HE (grade I-II) patients were included in whom LOLA was given in infusion form so efficacy of oral LOLA therapy still needs to be evaluated in patients with high grade HE.

\section{Nutritional Therapy}

Nutrition management is very important in the management of HE. Energy and nitrogen requirements in patients with HE are unlikely to differ substantially from those recommended in patients with cirrhosis per se viz.
$35-45 \mathrm{kcal} / \mathrm{g}$ and $1.2-1.5 \mathrm{~g} / \mathrm{kg}$ protein daily. Compliance is, however, likely to be a problem. Diets rich in vegetables and dairy protein may be beneficial and are therefore recommended, but tolerance varies considerably in relation to the nature of the staple diet. Branched chain amino acid supplements may be of value in the occasional patient intolerant of dietary protein. Short-term multivitamin supplementation should be considered in patients admitted with HE. Hyponatremia may worsen HE; it should be prevented as far as possible and should always be corrected slowly. ${ }^{44}$

\section{COMBINATION THERAPY FOR OVERT HEPATIC ENCEPHALOPATHY}

The evidence evaluating the use of combination therapy for the treatment of HE does not support its widespread use. The combination of rifaximin and lactulose may be considered in the treatment of HE and in patients refractory to monotherapy. ${ }^{45}$ However we have shown recently in a randomized controlled trial in patients with overt HE $(N=120)$ with mean CTP score $(9.7 \pm 2.8)$ and MELD score $(24.6 \pm 4.2)$ that $48(76 \%)$ patients in group A (rifaximin and lactulose) compared to $29(50.8 \%) \mathrm{pa}-$ tients in group B (lactulose alone) had complete reversal of HE $(P<0.004)$. There was significant decrease in mortality after treatment with lactulose plus rifaximin versus lactulose and placebo $(23.8 \%$ Vs $49.1 \%, P<0.05) .{ }^{46}$ Hence we recommend that combination of therapy should be practiced now for the treatment of HE.

\section{SECONDARY PROPHYLAXIS OF HEPATIC ENCEPHALOPATHY}

We defined secondary prophylaxis as preventing another episode of $\mathrm{HE}$ in patients who had a previous episode of HE. ${ }^{47}$ The emergence of HE after transjugular intrahepatic portosystemic shunt (TIPS) is of major concern for patients undergoing this procedure. Riggio and colleagues ${ }^{48}$ randomized seventy-five consecutive patients to receive lactitol $60 \mathrm{~mL} /$ day, rifaximin $1200 \mathrm{mg} /$ day or no treatment. Treatments were continued for 1 month post-TIPS or until the occurrence of an episode of HE. There was no significant difference in rate of HE occurrence among the three patient groups $(P=0.97)$.

Two recent clinical trials have been conducted to evaluate the efficacy of lactulose or rifaximin used concomitantly with lactulose, as secondary prophylaxis of overt HE compared with placebo. ${ }^{47,49}$ Sharma et $\mathrm{al}^{47}$ showed in 125 cirrhotic patients who had recovered from at least one previous episode of HE that significantly more patients in the placebo group (30 of 64 patients [46.8\%]) than in the lactulose group (12 of 61 patients [19.6\%]) developed HE $(P=0.001)$. Bass and colleagues ${ }^{49}$ enrolled 299 cirrhotic patients with a history of at least two episodes 
Table 3 Secondary Prophylaxis of Hepatic Encephalopathy.

\begin{tabular}{|c|c|c|c|c|c|c|}
\hline Trial & $\begin{array}{c}\text { Type of } \\
\text { prophylaxis }\end{array}$ & Study design & $\begin{array}{c}\text { No of } \\
\text { patient }(n)\end{array}$ & $\begin{array}{l}\text { Duration of } \\
\text { treatment }\end{array}$ & Assessment & Efficacy \\
\hline Riggio et al $^{48}$ & Primary & $\begin{array}{l}\text { Lactulose and lactitol in portosystemic } \\
\text { shunt }\end{array}$ & 31 & 6 months & PSE index & Lactulose $=$ lactitol \\
\hline $\begin{array}{l}\text { Sharma BC } \\
\text { et al }^{47}\end{array}$ & Secondary & $\begin{array}{l}\text { Lactulose (open-label) in cirrhosis with } \\
\text { previous HE }\end{array}$ & 140 & 14 months & $\begin{array}{l}\text { Psychometry } \\
\text { and CFF }\end{array}$ & Lactulose $>$ no treatment \\
\hline Bass et $\mathrm{al}^{49}$ & Secondary & $\begin{array}{l}\text { Rifaximin + lactulose (randomized, } \\
\text { double-blind, placebo-controlled) } \\
\text { in cirrhosis with previous HE }\end{array}$ & 299 & 6 months & HE clinical & Rifaximin > placebo \\
\hline Agrawal et al ${ }^{50}$ & Secondary & $\begin{array}{l}\text { Lactulose, probiotics (open-label trial) } \\
\text { in cirrhosis with previous HE }\end{array}$ & 235 & 12 months & $\begin{array}{l}\text { Psychometry } \\
\text { and CFF }\end{array}$ & Lactulose $=$ probiotics \\
\hline
\end{tabular}

of overt HE to receive either rifaximin (550 mg twice daily; $n=140)$ or placebo $(n=159)$ for a period of 6 months. More than $90 \%$ of patients in both groups were also maintained on concomitant lactulose therapy. A significantly lower percentage of patients in the rifaximin group (22.1\%) experienced a breakthrough $\mathrm{HE}$ episode during the study period than in the placebo group (45.9\%), with a hazard ratio (HR) of 0.42 (95\% CI 0.28, 0.64; $P<0.001)$. In addition, there was a significantly reduced risk of hospitalization in the rifaximin patient group when compared with placebo; $(13.6 \%$ vs $22.6 \%, P=0.01)$. The addition of rifaximin to a standard lactulose regimen may offer advantages in terms of decreasing risk of both breakthrough HE episodes as well as hospitalizations when compared with lactulose alone. So it is the addition of rifaximin to a standard lactulose regimen that adds advantage in terms of decreasing risk of both breakthrough HE episodes as well as hospitalizations when compared with lactulose alone. ${ }^{47}$ Recently our group also showed that lactulose and probiotics are equally effective for secondary prophylaxis of HE in patients with cirrhosis and probiotics could be an alternative to patients who are intolerant to lactulose ${ }^{50}$ (Table 3).

\section{CONCLUSION}

Complex pathophysiology and limited understanding of $\mathrm{HE}$ at present has led to limited therapy for the management of HE. Although the evidence for ammonia is robust, the synergistic role of inflammation and infection in modulating the cerebral effects of ammonia has been shown to be important. The most commonly utilized pharmacological agents still include the non-absorbable disaccharides lactulose and lactitol. Recent literature has supported the role of lactulose in both primary, secondary and treatment of covert and overt HE. Although antimicrobial agents such rifaximin have had an established role in the treatment of encephalopathy recent metaanalysis has shown efficacy of lactulose similar to antimicrobials. However studies enrolled in most of these metaanalysis are of poor quality that may have affect the overall results of these metaanalysis. Recently combining the rifaximin and lactulose has shown promising results in the treatment of overt HE which needs further validation in multicenter trials. Till we have more definitive agents non-absorbable disaccharides still continues to be the first-line therapy for overt hepatic encephalopathy.

\section{CONFLICTS OF INTEREST}

All authors have none to declare.

\section{REFERENCES}

1. Ferenci P, Lockwood A, Mullen K, Tarter R, Weissenborn K, Blei AT. Hepatic encephalopathy - definition, nomenclature, diagnosis, and quantification: final report of the working party at the 11th World Congresses of Gastroenterology, Vienna, 1998. Hepatology. 2002;35:716-721.

2. Riordan SM, Williams R. Treatment of hepatic encephalopathy. N Engl J Med. 1997;337:473-479.

3. Poordad FF. Review article: the burden of hepatic encephalopathy. Aliment Pharmacol Ther. 2007;25(suppl 1):3-92.

4. Bajaj JS, Wade JB, Sanyal AJ. Spectrum of neurocognitive impairment in cirrhosis: implications for the assessment of hepatic encephalopathy. Hepatology. 2009;50(6):2014-2021.

5. Bajaj JS, Cordoba J, Mullen KD, et al, International Society for Hepatic Encephalopathy and Nitrogen Metabolism (ISHEN). Review article: the design of clinical trials in hepatic encephalopathy-an International Society for Hepatic Encephalopathy and Nitrogen Metabolism (ISHEN) consensus statement. Aliment Pharmacol Ther. 2011 Apr;33(7):739-747.

6. Albrecht J, Zielińska M, Norenberg MD. Glutamine as a mediator of ammonia neurotoxicity: a critical appraisal. Biochem Pharmacol. 2010;80(9):1303-1308.

7. Bismuth M, Funakoshi N, Cadranel JF, Blanc P. Hepatic encephalopathy: from pathophysiology to therapeutic management. Eur $J$ Gastroenterol Hepatol. 2011;23(1):8-22.

8. Lockwood A, Yap E, Wong W. Cerebral ammonia metabolism in patients with severe liver disease and minimal hepatic encephalopathy. J Cereb Blood Flow Metab. 1991;11:337-341.

9. Häussinger D, Kircheis G, Fischer R, Schliess F, vom Dahl S. Hepatic encephalopathy in chronic liver disease: a clinical manifestation of astrocyte swelling and low grade cerebral edema. J Hepatol. 2000;32:1035-1038.

10. Blei AT, Cordoba. Hepatic encephalopathy. Am J Gastroenterol. 2001;96:1968-1976.

11. Clausen MR, Mortensen PB. Lactulose, disaccharides and colonic flora: clinical consequences. Drugs. 1997;53(6):930-942.

12. Cordóba J, Blei AT. Treatment of hepatic encephalopathy. Am J Gastroenterol. 1997;92(9):1429-1439. 
13. Simmons F, Goldstein H, Boyle JD. A controlled clinical trial of lactuIose in hepatic encephalopathy. Gastroenterology. 1970;59:827832.

14. Uribe M, Campollo O, Vargas F, Ravelli GP, Mundo F, Zapata L. Acidifying enemas (lactitol and lactose) vs. nonacidifying enemas (tap water) to treat acute portal-systemic encephalopathy: a doubleblind, randomized clinical trial. Hepatology. 1987;7:639-643.

15. Lanthier PL, Morgan MY. Lactitol in the treatment of chronic hepatic encephalopathy: an open comparison with lactulose. Gut. 1985;26:415-420.

16. Heredia D, Terés J, Orteu N, Rodés J. Lactitol vs. lactulose in the treatment of chronic recurrent portal-systemic encephalopathy. J Hepatol. 1988;7(1):106-110.

17. Riggio O, Balducci G, Ariosto F, et al. Lactitol in prevention of recurrent episodes of hepatic encephalopathy in cirrhotic patients with portal-systemic shunt. Dig Dis Sci. 1989;34(6):823-829.

18. Blanc P, Daures JP, Rouillon JM, et al. Lactitol or lactulose in the treatment of chronic hepatic encephalopathy: results of a metaanalysis. Hepatology. 1992;15(2):222-228.

19. Cammà C, Fiorello F, Tinè F, Marchesini G, Fabbri A, Pagliaro L. Lactitol in treatment of chronic hepatic encephalopathy. A meta-analysis. Dig Dis Sci. 1993;38(5):916-922.

20. Als-Nielsen B, Gluud LL, Gluud C. Non-absorbable disaccharides for hepatic encephalopathy: systematic review of randomised trials. BMJ. 2004;328(7447):1046.

21. Sharma P, Sharma BC. Profile of hepatic encephalopathy in children with cirrhosis and response to lactulose. Saudi J Gastroenterol. 2011;17(2):138-141.

22. Sharma P, Sharma BC, Sarin SK. Predictors of nonresponse to lactulose in patients with cirrhosis and hepatic encephalopathy. Eur J Gastroenterol Hepatol. 2010;22(5):526-531.

23. Conn HO, Leevy CM, Vlacevic ZR, Rodgers JB, Maddrey WC, Seef L. Comparison of lactulose and neomycin in the treatment of chronic portal-systemic encephalopathy. A double blind controlled trial. Gastroenterology. 1997;72:573-583.

24. Atterbury CE, Maddrey WC, Conn HO. Neomycin-sorbitol and lactulose in the treatment of acute portal-systemic encephalopathy. A controlled, double-blind clinical trial. Am J Dig Dis. 1978;23:398406.

25. Orlandi F, Freddara U, Candelaresi MT, Morettini A, Corazza GR, Di Simone A. Comparison between neomycin and lactulose in 173 patients with hepatic encephalopathy: a randomized clinical study. Dig Dis Sci. 1981;26:498-506.

26. Mullen K, Prakash R. Rifaximin for the treatment of hepatic encephalopathy. Expert Rev Gastroenterol Hepatol. 2010;4(6):665-677.

27. Festi D, Mazzella G, Orsini M. Rifaximin in the treatment of chronic hepatic encephalopathy: results of a multicenter study of efficacy and safety. Curr Ther Res. 1993;54(5):598-609.

28. Massa P, Vallerino E, Dodero M. Treatment of hepatic encephalopathy with rifaximin: double blind, double dummy study versus lactulose. Eur J Clin Res. 1993;4:7-18.

29. Mas A, Rodes J, Sunyer L, Rodrigo L, Planas R, Vargas V. Comparison of rifaximin and lactitol in the treatment of acute hepatic encephalopathy: results of a randomized, double-blind, doubledummy, controlled clinical trial. J Hepatol. 2003;38:51-58.

30. Paik YH, Lee KS, Han KH, et al. Comparison of rifaximin and lactulose for the treatment of hepatic encephalopathy: a prospective randomized study. Yonsei Med J. 2005;46(3):399-407.

31. Jiang $\mathrm{Q}$, Jiang $X \mathrm{H}$, Zheng $M H$, Jiang $L M$, Chen YP, Wang L. Rifaximin versus nonabsorbable disaccharides in the management of hepatic encephalopathy: a meta-analysis. Eur J Gastroenterol Hepatol. 2008;20(11):1064-1070.

32. Eltawil KM, Laryea M, Peltekian K, Molinari M. Rifaximin vs. conventional oral therapy for hepatic encephalopathy: a meta-analysis. World J Gastroenterol. 2012;18(8):767-777.
33. Di Piazza S, Filippazzo MG, Valenza LM, et al. Rifaximine versus neomycin in the treatment of portosystemic encephalopathy. Ital J Gastroenterol. 1991;23:403-407.

34. Parini P, Cipolla A, Ronchi M, Salzetta A, Mazzella G, Roda E. Effect of rifaximin and paromomycin in the treatment of portal-systemic encephalopathy. Curr Ther Res Clin Exp. 1992;52:34-39.

35. Pedretti G, Calzetti C, Missale G, Fiaccadori F. Rifaximin versus neomycin on hyperammoniemia in chronic portal systemic encephalopathy of cirrhotics. A double-blind, randomized trial. Ital J Gastroenterol. 1991;23:175-178.

36. Loguercio C, Abbiati R, Rinaldi M, Romano A, Del Vecchio Blanco C, Coltorti M. Long-term effects of Enterococcus faecium SF68 versus lactulose in the treatment of patients with cirrhosis and grade 1-2 hepatic encephalopathy. J Hepatol. 1995;23(1):39-46.

37. Loguercio C, Del Vecchio Blanco C, Coltorti M. Enterococcus lactic acid bacteria strain SF68 and lactulose in hepatic encephalopathy: a controlled study. J Int Med Res. 1987;15(6):335-343.

38. McGee RG, Bakens A, Wiley K, Riordan SM, Webster AC. Probiotics for patients with hepatic encephalopathy. Cochrane Database Syst Rev. 2011:9(11):CD008716.

39. Sushma S, Dasarathy S, Tandon RK, Jain S, Gupta S, Bhist MS. Sodium benzoate in the treatment of acute hepatic encephalopathy: a double-blind randomized trial. Hepatology. 1992;16(1):138-144.

40. Eriksson LS, Persson A, Wahren J. Branched-chain amino acids in the treatment of chronic hepatic encephalopathy. Gut. 1982 Oct;23(10):801-806.

41. Gluud LL, Dam G, Borre M, et al. Oral branched-chain amino acids have a beneficial effect on manifestations of hepatic encephalopathy in a systematic review with meta-analyses of randomized controlled trials. J Nutr. 2013 Aug;143(8):1263-1268.

42. Kircheis G, Nilius R, Held C, et al. Therapeutic efficacy of L-ornithine-L-aspartate infusions in patients with cirrhosis and hepatic encephalopathy: results of a placebo-controlled, double-blind study. Hepatology. 1998;25:1351-1360.

43. Bai M, Yang Z, Qi X, Fan D, Han G. L-ornithine-L-aspartate for hepatic encephalopathy in patients with cirrhosis: a meta-analysis of randomized controlled trials. J Gastroenterol Hepatol. 2013 May;28(5):783-792.

44. Amodio P, Bemeur C, Butterworth R, et al. The nutritional management of hepatic encephalopathy in patients with cirrhosis: International Society for Hepatic Encephalopathy and Nitrogen Metabolism Consensus. Hepatology. 2013 Jul;58(1):325-336.

45. Mohammad RA, Regal RE, Alaniz C. Combination therapy for the treatment and prevention of hepatic encephalopathy. Ann Pharmacother. 2012 Nov;46(11):1559-1563.

46. Sharma BC, Sharma P, Lunia MK, Srivastava S, Goyal R, Sarin SK. A randomized, double-blind, controlled trial comparing rifaximin plus lactulose with lactulose alone in treatment of overt hepatic encephalopathy. Am J Gastroenterol. 2013 Sep;108(9):1458-1463.

47. Sharma BC, Sharma P, Agrawal A, Sarin SK. Secondary prophylaxis of hepatic encephalopathy: an open-label randomized controlled trial of lactulose versus placebo. Gastroenterology. 2009 Sep;137(3):885-891.

48. Riggio O, Masini A, Efrati C, et al. Pharmacological prophylaxis of hepatic encephalopathy after transjugular intrahepatic portosystemic shunt: a randomized controlled study. J Hepatol. 2005;42:674-679.

49. Bass NM, Mullen KD, Sanyal A, et al. Rifaximin treatment in hepatic encephalopathy. N Engl J Med. 2010 Mar 25;362(12):10711081.

50. Agrawal A, Sharma BC, Sharma P, Sarin SK. Secondary prophylaxis of hepatic encephalopathy in cirrhosis: an open-label, randomized controlled trial of lactulose, probiotics, and no therapy. Am J Gastroenterol. 2012 Jul;107(7):1043-1050. 